\title{
Perception of dental care among children
}

\author{
Cláudia Lobelli Rangel Gomes', Manoelito Ferreira Silva-Júnior ${ }^{2}$, Ana Lílian Correia Lopes ${ }^{3}$, Symone Fernandes de \\ Melo ${ }^{4}$, Manuel Antonio Gordón-Núnez ${ }^{5}$, Isabelita Duarte Azevedo 6 \\ 'Universidade de Campinas - UNICAMP, Piracicaba Dental School, Department of Pediatric Dentistry, Piracicaba, SP, Brazil \\ 2Universidade de Campinas - UNICAMP, Piracicaba Dental School, Department of Community Dentistry, Piracicaba, SP, Brazil \\ ${ }^{3}$ Exército Brasileiro and Hospital Geral de Belém, Belém, PA, Brazil \\ ${ }^{4}$ Universidade Federal do Rio Grande do Norte - UFRN, Department of Psychology, Area of Psychology, Natal, RN, Brazil \\ 5Universidade Estadual da Paraiba - UEPB (Campus VIII), Departament of Dentistry, Area of Pathological Processes, Araruna, PB, Brazil \\ ${ }^{6}$ Universidade Federal do Rio Grande do Norte - UFRN, Dental School, Departament of Dentistry, Area of Pediatric Dentistry, Natal, RN, Brazil
}

Received for publication: October 15, 2016 Accepted: March 08, 2017

Correspondence to: Isabelita Duarte Azevedo Departamento de Odontologia (Área de Odontopediatria) Avenida Senador Salgado Filho, 1787, Lagoa Nova CEP: $59.056-000$ Natal-RN, Brazil Phone: +55 84 3215-4100

E-mail : isabelitaduarte@hotmail.com

\section{Abstract}

Children that come to dental offices with fear and anxiety usually tend to resist conditioning mechanisms. Aim: To evaluate children's perception of dental treatment and to identify the factors influencing this perception. Methods: For this study, we selected a random sample of 100 children of both genders aged 3 to 12 , treated at the Department of Dentistry of a University (Group I) and at a Children's Hospital (Group II). A structured questionnaire about the child's perception about dental care was applied and the children were asked to draw a picture of this topic. Results: Most children expressed a positive perception in the questionnaire and in the drawings (93.8\%). This positive perception was more accentuated in Group I (94\%) and in children aged 3 to 5 years $(100 \%)$, particularly in girls $(78 \%)$. The main cause of fear was the use of needles $(42.4 \%)$. Many children (24.2\%) reported to prefer the noninvasive procedures. Conclusions: A positive perception of dental treatment was observed in most children. Therefore, dental pediatricians must be aware of the children's perception for establishing a better conditioning.

Keywords: Psychology, Child, Fear, Pediatric Dentistry.

\section{Introduction}

Knowledge of the child's perception about dental care helps understanding the causes of the fear and anxiety, as well as about what is happening in this universe during dental treatment. The false image of torture in the dentist chair seems to occupy the imagination of many children that arrive at dental offices with this pre-established concept and resist conditioning mechanisms. It is therefore important to make sure that children feel comfortable during their dental visit and consequently have a positive experience ${ }^{1-3}$. Negative experiences are difficult to overcome, especially when they were the child's first impression of dental care ${ }^{1,4,5}$.

Safe methods to identify the feelings of children are important to establish the adequate dental treatment. For this purpose, questionnaires are useful tools to evaluate a child's perception of dental treatment by the professional, which use exclusively the verbal information provided by the patients ${ }^{3,5-7}$. Drawings are better since they do not require direct responses and help express feelings which the child is not aware of or unable to express verbally ${ }^{8-10}$.

Identification of the causes of fear and anxiety is of utmost importance for the adequate management of pediatric patients. In this context, the aim this study was to evaluate children's perception of dental treatment and to identify factors that influence this perception. 


\section{Material and methods}

The study was approved by the Ethics Committee of the Federal University of Rio Grande do Norte (UFRN) (protocol $375 / 10)$. The parents or legal guardians received detailed information about the objectives and methods of the study and agreed to their children's participation by signing the free informed consent form.

The sample size calculation was performed using the literature data11 on the proportion of dental anxiety in children as being $84 \%$, absolute precision of $10 \%$ and a significance level of $5 \%$. The sample size was 52 for each group, totaling 104 individuals. There was a loss of 4 individuals from the sample size $(3.84 \%)$. A random sample of 100 children of both genders was selected, with ages ranging from 3 to 12 years. Fifty children were seen at the Department of Dentistry, UFRN (Group I), and 50 were recruited from the Varela Santiago Children's Hospital, Natal, RN, Brazil (Group II).

A structured questionnaire with objective and subjective questions about the perception of dental care was applied to each child. The researcher filled out the questionnaire according to the verbal answers of the child.

After application of the questionnaire, the child received a white paper, a box of wooden color pencils, a box of color crayons, a pencil and an eraser. The box of pencils was opened and all available colors were shown to the child. The child was then asked to make a drawing about the topic "How do you perceive dental care?" According to Marshman and Hall ${ }^{12}$, drawings may be used in several ways to investigate children and their relationship with dentistry. There was no time limit for this task.

The child received no verbal encouragement during drawing and the researcher waited for the signal from the child when he/ she finished the task. The researcher then collected the drawing and recorded the caption dictated by the child. On the back of the sheet, the examiner recorded the child's name and age, date, code corresponding to the sample number and description of the drawing as reported by the child, asking the child to confirm the contents. The figure caption contained the identification and description of each element drawn by the child, as well as the feelings present in the image.

The perception of dental care expressed in the drawing was classified according to the child's verbal interpretation of the drawing (Figure 1) to psychological interpretation, categorized in four groups: positive, negative, ambivalent or neutral. The drawings were analyzed by the method proposed by Taylor et al. ${ }^{13}$, based on the occurrence (frequency) of some items. It was classified as positive when the image and caption revealed positive feelings about dental care (Presence of elements of a cheerful and calm environment, such as a smile on the face of the child or the dentist); negative, when these elements revealed negative feelings about dental care (presence of sad or fearful elements, such as when the child's face showed fear, crying, angry, sad or the dentist's figure as a torturer or a bad guy); ambivalent, when positive and negative elements were perceived during interpretation of the drawing (when the design presented elements both positive and negative, as in the previous categories and we were not able to determine the child's feeling); neutral (when it was not possible to establish the feeling, but it was categorized when we were unable to verify any well-defined characteristics; neither positive or negative) present in the drawing and especially in the explanation present in the legend given after the finalization of the drawing (Figures 1a to 1c).
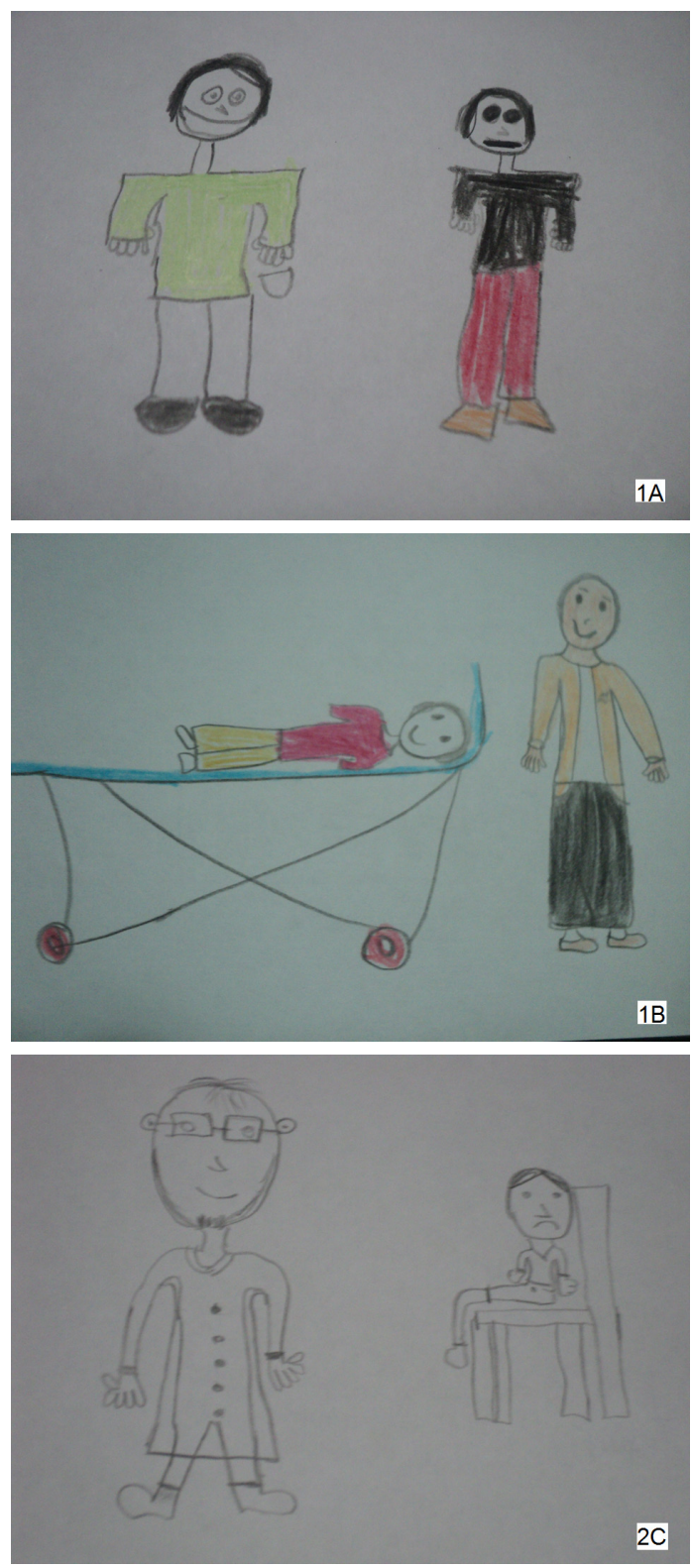

Figure 1 - Classification of the drawings. a) Drawing with ambivalent perception. The figure on the left side of the image was called by the child a "good dentist". The one on the right side was called a "bad dentist". Note the light colors, harmony of lines and cheerful aspect of the figure on the left, whereas strong colors, irregular lines and a face with empty eyes and somber expression are seen on the right. b) Drawing with positive perception. This drawing was collected from Group II. Observe the harmony of smiling individuals. Notice the influence of the hospital environment on the representation of the dental chair which resembles a gurney. c) Drawing with negative perception. Notice the sad expression on the face of the figure on the right, as well as the absence of color throughout the drawing. Natal/ RN, Brazil, 2011. 
For the purpose of statistical and descriptive analysis of the child's perception found in the drawing in relation to the results of the questionnaire, the question "Do you like to go to the dentist?" was considered as indicative of the child's perception, obtained with the questionnaire. The dichotomous answers "yes" or "no" corresponded to a positive or negative perception, respectively.

The collected data were entered in a database and analyzed using the Statistical Package for the Social Sciences 18.0 (SPSS Inc., Chicago, IL, USA). Questionnaire data were compared with the psychological interpretation of the child's perception of dental care obtained from the drawings. The results were reported as means, absolute and relative frequencies, compared by the chisquared or Fisher's exact test at a 5\% statistical significance level.

\section{Results}

Most children expressed a positive perception of dental care both in the drawing (91\%) and in the questionnaire (81\%). This positive perception was also observed when the questionnaire and drawings were analyzed together $(72 \%)$.

Table 1 shows the distribution of dental care perception expressed in the questionnaire according to gender, age group, institution and getting little gifts. No significant difference in the perception of dental care was observed between genders $(p=0.682)$. There was a significant association between the perception of dental care and the institution where the participants were enrolled ( $p=0.005)$, with a higher frequency of positive perception among children from the Department of Dentistry of UFRN (Group I).

Table 1 - Distribution of dental care perception expressed in the questionnaire according to gender, age group, institution and getting little gifts. Natal/RN, Brazil, 2011.

\begin{tabular}{|c|c|c|c|c|}
\hline \multirow{2}{*}{\multicolumn{2}{|c|}{ Variable }} & \multicolumn{3}{|c|}{ Variable perception on dental care } \\
\hline & & Positive $-\mathrm{n}(\%)$ & Negative- $\mathrm{n}(\%)$ & $\mathrm{p}$-value \\
\hline \multirow{3}{*}{ Gender } & Female & $34(82.9)$ & $7(17.1)$ & \multirow{3}{*}{$0.682^{*}$} \\
\hline & Male & $47(79.7)$ & $12(20.3)$ & \\
\hline & Total & $81(81.0)$ & $19(19.0)$ & \\
\hline \multirow{4}{*}{ Age } & 3- 5 years & $10(100.0)$ & $0(0.0)$ & \multirow{4}{*}{$0.255^{\star *}$} \\
\hline & $6-8$ years & $33(80.5)$ & $8(19.5)$ & \\
\hline & $9-12$ years & $38(77.6)$ & $11(22.4)$ & \\
\hline & Total & $81(81.0)$ & $19(19.0)$ & \\
\hline \multirow{3}{*}{ Group } & Group I & $46(56.8)$ & $4(21.1)$ & \multirow{3}{*}{$0.005^{\star *}$} \\
\hline & Group II & $35(43.2)$ & $15(78.9)$ & \\
\hline & Total & $81(81.0)$ & $19(19.0)$ & \\
\hline \multirow{3}{*}{ Gifts } & Yes & $22(27.2)$ & $4(21.1)$ & \multirow{3}{*}{$0.585^{\star *}$} \\
\hline & No & $59(72.8)$ & $15(78.9)$ & \\
\hline & Total & $81(81.0)$ & $19(19.0)$ & \\
\hline
\end{tabular}

${ }^{*}$ Chi-square test. ${ }^{*}$ Fisher's exact test.

Table 2 shows the distribution of dental care perception expressed in the drawings, according to gender, age group, institution and getting little gifts. Descriptive analysis of the psychological interpretation of the drawings revealed a higher

percentage of positive perception among boys compared to girls. As regards the age group, the results were similar to those obtained with the questionnaire, showing a higher frequency of positive perception in children aged 3-5 years, followed by those aged 6-8 years and 9-12 years. Analysis of the institution from which the children were recruited showed a higher percentage of positive perception in Group I compared to Group II. There was no association between the perception expressed in the drawing and getting or not little gifts, similar to the results obtained from the questionnaire.

Table 2 - Distribution of dental care perception expressed in the drawing according to gender, age group, institution and getting little gifts. Natal/RN, Brazil, 2011.

\begin{tabular}{|c|c|c|c|c|c|}
\hline \multirow{2}{*}{\multicolumn{2}{|c|}{ Variable }} & \multicolumn{3}{|c|}{ Variable perception on dental care } & \multirow{3}{*}{$\frac{\text { Ambivalent }}{n(\%)}$} \\
\hline & & Positive & Negative & Neutral & \\
\hline & & $\mathrm{n}(\%)$ & $n(\%)$ & $\mathrm{n}(\%)$ & \\
\hline \multirow{3}{*}{ Gender } & Female & $54(91.5)$ & $1(1.7)$ & $1(1.7)$ & $3(5.1)$ \\
\hline & Male & $37(90.2)$ & $2(4.9)$ & $0(0.0)$ & $2(4.9)$ \\
\hline & Total & $91(91.0)$ & $3(3.0)$ & $1(1.0)$ & $5(5.0)$ \\
\hline \multirow{4}{*}{ Age } & $3-5$ years & $10(100.0)$ & $0(0.0)$ & $0(0.0)$ & $0(0.0)$ \\
\hline & $6-8$ years & $38(92.7)$ & $1(2.4)$ & $0(0.0)$ & $2(4.9)$ \\
\hline & $9-12$ years & $43(87.8)$ & $2(4.1)$ & $1(2.0)$ & $3(6.1)$ \\
\hline & Total & $91(91.0)$ & $3(3.0)$ & $1(1.0)$ & $5(5.0)$ \\
\hline \multirow{3}{*}{ Group } & Group I & $48(96.0)$ & $1(2.0)$ & $0(0.0)$ & $1(2.0)$ \\
\hline & Group II & $43(86.0)$ & $2(4.0)$ & $1(2.0)$ & $4(8.0)$ \\
\hline & Total & $91(91.0)$ & $3(3.0)$ & $1(1.0)$ & $5(5.0)$ \\
\hline \multirow{3}{*}{ Gifts } & Yes & $23(88.5)$ & $0(0.0)$ & $1(3.8)$ & $2(7.7)$ \\
\hline & No & 68 (91.9) & $3(4.1)$ & $0(0.0)$ & $3(4.1)$ \\
\hline & Total & $91(91.0)$ & $3(3.0)$ & $1(1.0)$ & $5(5.0)$ \\
\hline
\end{tabular}

The frequency of dental treatment fear was higher among boys $(63.6 \%)$ than girls $(36.4 \%)$. Fear was reported by 16 $(39.0 \%)$ children aged 6-8 years and by $17(34.7 \%)$ aged $9-12$ years. With respect to the institution from where the children were recruited, the percentage of fear of dental treatment was higher in Group II (46.0\%) than in Group I (20.0\%).

The reasons for preference for tooth extraction in the dental office or in any other place are presented in Table 3. Attitudes of the dentist that children do not like are shown and attitudes that the dentist could use improve the visit are shown in Table 4.

Table 3 - Distribution of the sample according to preference of tooth removal in the dental office or at any other place. Natal/ RN, Brazil, 2011.

\begin{tabular}{ll}
\hline \multicolumn{1}{c}{ Reasons of preference for tooth extraction in the dental office or another place } \\
\hline \multicolumn{1}{c}{ Office } & \multicolumn{1}{c}{ Other place } \\
\hline $10(37.03 \%)$ Positive feelings to the dentist* & $11(44 \%)$ Less pain \\
$8(29.62 \%)$ They feel less pain & $7(28 \%)$ Less fear \\
$3(11.1 \%)$ They feel less afraid & $4(16 \%)$ Fear of anesthesia \\
$3(11.1 \%)$ Receive anesthesia & $1(4 \%)$ Preferred dental floss \\
$1(3.7 \%)$ Difficulty in getting elsewhere & $1(4 \%)$ Fear of plier extraction \\
$1(3.7 \%)$ Increased bleeding outside the office & $1(4 \%)$ Not like the office \\
$\begin{array}{ll}1(3.7 \%) \text { Can cry without recrimination } \\
28(50.0 \%) \text { Total }\end{array}$ \\
$\begin{array}{ll}{ }^{*} \text { Attitudes and characteristics of the dentist, reported by the children, which provide } \\
\text { more confidence during the visit, for example, patience of the dentist, an affectionate }\end{array}$ \\
$\begin{array}{ll}\text { approach and the fact that the dentist explains the procedure before performing it. }\end{array}$
\end{tabular}


Table 4 - The attitudes or procedures of the dentist that the child reported not to like and the opinion of the child about the attitudes the dentist could assume to improve the visit. Natal/RN, Brazil, 2011.

\begin{tabular}{lc}
\hline \multicolumn{2}{c}{ The attitudes of the dentist reported not to like } \\
\hline Invasive procedures & $29.0 \%$ \\
Use of needles & $28.0 \%$ \\
They couldn't answer & $11.0 \%$ \\
Negative behavior of the dentist & $11.0 \%$ \\
Nothing unpleasant & $6.0 \%$ \\
High and low speed dental & $5.0 \%$ \\
Non-invasive procedures & $3.0 \%$ \\
Staying long with the mouth open & $3.0 \%$ \\
Light reflector on the eyes & $2.0 \%$ \\
I do not like when the dentist messes in my teeth & $2.0 \%$ \\
\hline \multicolumn{2}{c}{ Attitudes the dentist could assume to improve the visit } \\
\hline Positive behavior of dentist & $31.0 \%$ \\
They couldn't answer & $22.0 \%$ \\
Receiving gifts & $18.0 \%$ \\
No anesthesia and no needle & $8.0 \%$ \\
Getting braces put on & $5.0 \%$ \\
Using anesthesia & $4.0 \%$ \\
X-rays & $3.0 \%$ \\
Visit no anesthesia and extraction & $2.0 \%$ \\
Use of triple syringe & $2.0 \%$ \\
Extractions & $2.0 \%$ \\
Oral prescription medication & $1.0 \%$ \\
Toys in the office & $1.0 \%$ \\
Don't need nothing, the dentist is already nice & $1.0 \%$ \\
\hline
\end{tabular}

\section{Discussion}

The technical advances and increasing progress in prevention of oral diseases over the past decades led to the improvement of pain management in dental practice. However, many patients are still afraid of the dentist ${ }^{14}$. Fear of dental treatment has been recognized as one of the leading problems in pediatric dentistry. Children with fear tend to visit the dentist less often, compromising their oral health. However, the etiology of this fear is not completely understood $^{15}$.

The anxiety and fear of dental treatment in pediatric patients have been recognized as potential problems for the management of these patients. Early recognition and management of dental fear are critical to win the child's confidence and for efficient treatment ${ }^{16}$. In the present study, the prevalence of fear during dental treatment was $33 \%$. Similar results have been reported by Nicolas et al. ${ }^{14}$, who observed a prevalence of fear of $24.3 \%$, and by Oliveira and Colares ${ }^{17}$ who found a prevalence of dental anxiety of $34.7 \%$.

Most of the children who reported to be afraid to go to the dentist $(33.3 \%)$ were boys $(63.6 \%)$ aged 6 to 8 years $(39.0 \%)$. Some studies have found higher prevalence of anxiety among girls ${ }^{3,14}$. According Nicolas et al. ${ }^{14}$, this finding is likely to be associated with cultural influences such as the fact that boys are uncomfortable to admit their fear and anxiety since this is not the behavior of a "manly man".
On the other hand, studies observed no significant difference of influence in dental fear ${ }^{18}$ and dental anxiety ${ }^{1,9}$ between genders. A possible explanation could be the different factors able to trigger dental fear among boys and girls. A recent study using the Children's Fear Survey Schedule - Dental Subscale showed some differences between girls and boys. For girls, four factors were found ('fear of usual dental procedures and injections'; 'fear of strangers'; 'fear of general medical aspects of treatment'; 'fear of health care personnel'). However, for boys, five factors were identified ('fear of usual dental procedures'; 'fear of general medical aspects of treatment'; 'fear of invasive dental procedures'; 'fear of health care personnel and injections'; 'fear of strangers') ${ }^{6}$. Thus, further studies are required to identify the gender peculiarities in relation to dental fear, and not just to find which gender has more prevalence of fear or which has a higher association with dental fear.

Studying the influence of age, the fear and anxiety appear to decrease with increasing age, due to the progressively greater number of experiences with oral problems and dental care ${ }^{5,7}$. Dutt et al. ${ }^{16}$ found a predominance of dental fear among older children. In contrast, Lee et al. ${ }^{15}$ reported that children younger than 4 years were significantly more anxious than children over 7 years. In another study, younger children cried more frequently during dental treatment than older children, a finding that can be explained by the fact that crying is usually a physiological expression of aggressive behavior in younger children ${ }^{4}$. These results disagree with the present study in which only children aged 3-5 years were not afraid to go to the dentist and children aged 9-12 years were less afraid than children of the 6-8 year age group. In contrast, the above studies did not observe significant association between age and dental anxiety ${ }^{3,19}$. The influence of age on anxiety during dental treatment is still unclear, since few studies have investigated this topic ${ }^{14}$.

The results of the present study did not reveal a significant association between the child's perception of dental care expressed in the drawing or questionnaire and the fact of getting or not little gifts. Thus, this factor does not seem to influence the child's perception of dental care.

In the present study, the child's perception of dental care was positive in most cases, as expressed by the drawings and questionnaires. This finding agrees with the results reported by AlSarheed ${ }^{4}$ who used a questionnaire to evaluate children's attitudes towards dentists and observed that most children reported liking their visit to the dentist, whereas a low percentage of the sample stated they did not like the visit to the dentist and feel afraid.

Few studies used children's drawings as an instrument to evaluate subjective feelings. However, drawings have been shown to be a useful and valid tool to capture the emotional state of a child in dental settings, since drawing is easier, familiar and more enjoyable for the child patient ${ }^{9,10}$. Children present difficulties 
with the abstract task of describing subjective experiences using verbal language and rather match internal states better with pictorial representations of their emotions ${ }^{20-23}$. Studies suggested that projective techniques are a more adequate measure to collect data about a child's perception ${ }^{21,23}$. Children's drawings and their description can provide a unique window into their inner experiences, particularly when they experience stress or anxiety ${ }^{24}$. In clinical practice, drawings have been used for decades by child psychiatrists and psychologists to analyze the subjectivity of children's feelings, their fears, anxiety, concerns and anger ${ }^{23}$. The use of non-verbal assessment tools like drawings is more appealing since this method overcomes language limitations and cultural barriers that might be encountered with traditional verbal tests $^{25}$. Drawing helps children organize their narrative which, in turn, gives them the opportunity to find their voice ${ }^{9,26}$.

The drawings of hospitalized children have been shown to be a valuable assessment tool to measure their emotional state ${ }^{20}$. In the present study, the frequency of dental fear was higher in the group of hospitalized children (Group II, 46\%) than among children seen at the Dentistry Department of a University (Group I, 20\%). According to Themessl-Huber et al. ${ }^{27}$, dental fear in hospitalized children is usually associated with negative medical and dental experiences of these children. The frequency of dental fear in hospitalized children ranged from $5 \%$ to $20 \%$ in another study $^{28}$. This percentage was $33 \%$ in the present investigation.

The use of needles and tooth extraction were the main reasons of dental fear reported by most children of the sample. Similar results have been reported, like local anesthesia, mainly the use of a needle and the tooth extraction associated with pain, were the most common reasons cited by children who did not like dental treatment ${ }^{4,7}$.

When the children were asked about their preference of undergoing tooth extraction in the dental office or at any other place, half the children $(50 \%)$ preferred to be treated in the dental office. The most frequently reported reason for this preference was the positive attitude of the dentist (37\%). Most children $(31 \%)$ provided the same answer, i.e., a positive attitude of the dentist, when they were asked about what the dentist could do to improve the visit. According to AlSarheed ${ }^{4}$, dental surgeons have to be aware of the perception, preferences and fears of the patient, since children who have a positive interaction with their dentist are less likely to develop fear during the visits.

Several factors, such as experience of oral problems, number of tooth extractions, number of invasive treatments, number of visits before the first invasive treatment, management of behavior problems, parents' fear of dental treatment and classification of dental fear, are significantly associated with the level of the child's fear of dental treatment ${ }^{1,5}$. Studies have shown that visiting the dentist more regularly and without previous traumatic dental experiences made the patient less anxious ${ }^{1,3}$. Berge et al. ${ }^{1}$ observed that children with more noninvasive visits are less likely to develop dental fear than those with a previous invasive experience. These findings agree with the present study where most children cited noninvasive procedures as the ones they liked most during dental treatment. Tickle et al. ${ }^{2}$ also showed that a history of extractions and asymptomatic dental visits were significantly associated with anxiety, suggesting that the etiology of dental anxiety in children is multifactorial.

A study about the understanding of children enrolled in an Oral Health Education Programs on tooth care showed satisfactory knowledge, mainly on positive and negative aspects related to the oral health-disease process ${ }^{10}$, and not associating with negative professional aspect and dental care. Programs like this must be encouraged to disassociate oral care form negative aspects. Besides that, the results of the present study indicate the need for strategies designed to promote constant asymptomatic visits to the dentist at an early age. Dental professionals need to understand the etiology of dental anxiety in children and its development over time in order to provide a more effective care to their patients and therefore, to minimize the risk of developing anxiety ${ }^{2}$. Employing scales that measure fear, as Children's Fear Survey Schedule - Dental Subscale, the dentist may recognize which item(s) of the scale reported by the child were related to a particular fear. Accordingly, the dentist can approach the child and guide his/her behavior during the dental visit ${ }^{6}$. In most cases, anxiety towards dental treatment has its origin in childhood and, if not overcome, may extend into adult life, compromising oral health ${ }^{29}$.

Our study verified that most children of the sample expressed a positive perception of dental care in both the drawing and questionnaire. The diverse instruments used in our study for the evaluation of the child's perception of dental care, are important tools for the investigation of perceptions, attitudes and behaviors of child patients designed to improve the quality of dental care in this population. Besides that, dental professionals have to be aware of the perception, preferences and fears of the patient for better conditioning and for a good doctor-patient relationship.

\section{References}

1. Berge MT, VeerKamp JSJ, Hoogstraten J. The etiology of childhood dental fear: the role of dental and conditioning experiences. J Anxiety Dis. 2002; 16(3): 321-9.

2. Tickle M, Jones C, Buchannan K, Milsom KM, Blinkhorn AS, Humphris GM. A prospective study of dental anxiety in a cohort of children followed from 5 to 9 years of age. Int J Paediatr Dent. 20092009 Jul;19(4):22532. doi: 10.1111/j.1365-263X.2009.00976.x

3. Saatchi M, Abtahi M, Mohammadi G, Mirdamadi M, Binandeh ES. The prevalence of dental anxiety and fear in patients referred to Isfahan Dental School, Iran. Dent Res J (Isfahan). 2015 May-Jun;12(3):248-53.

4. AlSarheed M. Children's Perception of Their Dentists. Eur J Dent. 2011 
Apr;5(2):186-90.

5. Olak J, Saag M, Honkala S, Nõmmela R, Runnel R, Honkala E, et al. Children's dental fear in relation to dental health and parental dental fear. Stomatologija. 2013;15(1):26-31.

6. El-Housseiny AA, Alamoudi NM, Farsi NM, El Derwi DA. Characteristics of dental fear among Arabic-speaking children: a descriptive study. BMC Oral Health. 2014 Sep;14:118. doi: 10.1186/1472-6831-14-118.

7. Oliveira MG, Ávila RA, Silva RRC, Gomes FV, Moraes JFD, Weber JBB. Dental fear and anxiety among children and their caregivers. Rev Cienc Med Biol. 2014 May-Aug;13(2):137-41. Doi: http://dx.doi. org/10.9771/cmbio.v13i2.10113.

8. Hamama L, Ronen T. Children's drawings as a self-report measurement. Child Family Social Work. 2009;14(1):90-102.

9. Torriani DD, Goettems ML, Cademartori MG, Fernandez RR, Bussoletti DM. Representation of dental care and oral health in children's drawings. Br Dent J. 2014 Jun;216(12):E26. doi: 10.1038/ sj.bdj.2014.545.

10. Pacheco KTS, Silva-Junior MF, Arcieri RM, Garbin AJI, Garbin CAS. The knowledge of children on tooth care: a qualitative and quantitative approuch. Rev Odonto Cienc. 2016;31(2):49-53.

11. Bottan ER, Oglio JD, Araújo SM. Dental anxiety in elementary schoolchildren. Pesq Bras Odontoped Clin Integr. 2007;7(3):241-6.

12. Marshman Z, Hall MJ. Oral health research with children. Int J Paediatr Dent. 2008 Jul;18(4):235-42. doi: 10.1111/j.1365-263X.2008.00922.x.

13. Taylor D, Roth $\mathrm{G}$, Mayberry W. Children's drawings about dentistry. Community Dent Oral Epidemiol. 1976 Jan;4(1):1-6.

14. Nicolas E, Bessadet M, Collado V, Carrasco P, Rogerleroi V, Hennequin M. Factors affecting dental fear in French children aged $5-12$ years. Int J Paediatr Dent. 2010 Sep 1;20(5):366-73. doi: 10.1111/j.1365263X.2010.01054.x.

15. Lee $\mathrm{C}$, Chang $\mathrm{Y}$, Huang $\mathrm{S}$. The clinically related predictors of dental fear in Taiwanese children. Int J Paediatr Dent. 2008 Nov;18(6):415-22. doi: 10.1111/j.1365-263X.2008.00924.x.

16. Dutt K, Nagar A, Pandey R, Singh P. Reliability and factor analysis of children's fear survey schedule-dental subscale in Indian subjects. J Indian Soc Pedod Prev Dent. 2010 Jul-Sep;28(3):151-5. doi: 10.4103/0970-4388.73788.

17. Oliveira MMT, Colares V. The relationship between dental anxiety and dental pain in children aged 18 to 59 months: a study in Recife, Pernambuco State, Brazil. Cad Saude Publica. 2009 Apr;25(4):743-50.

18. Klaassen MA, Veerkamp JSJ, Hoogstraten J. Dental fear, communication, and behavioural management problems in children referred for dental problems. Int J Paediatr Dent. 2007 Nov;17(6):469-77.

19. Jones LM, Buchanan H. Assessing children's dental anxiety in New Zealand. N Z Dent J. 2010 Dec;106(4):132-6.

20. Clatworthy S, Simon K, Tiedeman M. Child Drawing: Hospital - an instrument designed to measure the emotional status of hospitalized schoolaged children. J Pediatr Nurs. 1999 Feb;14(1):2-9.

21. Clatworthy S, Simon K, Tiedeman M. Child drawing: hospital manual. J Pediatr Nurs. 1999 Feb;14(1):10-8.

22. Chambers CT, Giesbrecht K, Craig KD, Bennet SM, Huntsman E. A comparison of faces for the measurement of pediatric pain: children's and parents' ratings. Pain 1999 Oct;83(1):25-35.

23. Skybo TH, Ryan-Wenger N, Su Y. Human figure drawings as a measure of children's emotional status: critical review for practice. J Pediatr Nurs. 2007 Feb; 22(1):15-28.

24. Looman WS. A developmental approach to understanding drawings and narratives from children displaced by Hurricane Katrina. J Pediatr Health Care. 2006 May-Jun;20(3):158-66.

25. Matto HC. Drawing in clinical assessment of children and adolescent. In: Smith SR, Handler L. The Clinical Assessment of Children and Adolescents: A Practitioner's Handbook. Mahwah, NJ: Lawrence Erlbaum Associates; 2006. p.207-9.

26. Driessnack M. Children's drawings as facilitators of communication: a meta-analysis. J Pediatr Nurs. 2005 Dec;20(6):415-23.

27. Themessl-Huber M, Freeman R, Humphris G, Macgillivray S, Terzi N. Empirical evidence of the relationship between parental and child dental fear: a structured review and meta-analysis. Int J Paediatr Dent. 2010 Mar;20(2):83-101. doi: 10.1111/j.1365-263X.2009.00998.x.

28. Klingberg G, Broberg AG. Dental fearanxiety and dental behaviour management problems in children and adolescents: a review of prevalence and concomitant psychological factors. Int J Paediatr Dent. 2007 Nov;17(6):391-406.

29. Oliveira RS, Torres LMS, Gomes IS, Nicoló RD. [Evaluation of anxiety levels in children during odontological treatment]. IJD, Int J Dent. 2010 Oct-Dec;9(4):193-7. 